\title{
Effects of Ginseng Total Saponins on Pacemaker Currents of Interstitial Cells of Cajal from the Small Intestine of Mice
}

\author{
Hyun Soo Kim, ${ }^{a}$ Shankar Prasad Parajuli, ${ }^{b}$ Cheol Ho Yeum,${ }^{b}$ Jong Seong Park, ${ }^{c}$ Han Seong Jeong, ${ }^{c}$ \\ Insuk So, ${ }^{d} \mathrm{Ki}$ Whan $\mathrm{KIM}^{d}{ }^{d} \mathrm{Jae}$ Yeoul Jun, ${ }^{b}$ and Seok CHOI ${ }^{*}, b$ \\ ${ }^{a}$ Division of Gastroenterology, Department of Internal Medicine, Chonnam National University Medical School; \\ ${ }^{c}$ Department of Physiology, Chonnam National University Medical School; Gwangju 501-757, Korea: ${ }^{b}$ Department of \\ Physiology, College of Medicine, Chosun University; 375 Seosuk-dong, Gwangju 501-759, Korea: and ${ }^{d}$ Department of \\ Physiology and Biophysics, College of Medicine, Seoul National University; Seoul 110-799, Korea. \\ Received May 1, 2007; accepted July 26, 2007
}

\begin{abstract}
Although ginsenosides have a variety of physiologic or pharmacologic functions in various regions, there are only a few reports on the effects of ginsenosides on gastrointestinal (GI) motility. We studied the modulation of pacemaker activities by ginseng total saponins in the interstitial cells of Cajal (ICC) using the whole cell patchclamp technique. Externally applied ginseng total saponins (GTS) produced membrane depolarization in the current-clamp mode and increased tonic inward pacemaker currents in the voltage-clamp mode. The application of flufenamic acid or niflumic acid abolished the generation of pacemaker currents, but only treatment with flufenamic acid inhibited the GTS-induced tonic inward currents. The tonic inward currents induced by GTS were not inhibited by the intracellular application of guanosine $5^{\prime}-[\beta$-thio]diphosphate trilithium salt. Pretreatment with a $\mathrm{Ca}^{2+}$-free solution, with $\mathrm{U}-73122$, an active phospholipase $\mathrm{C}$ inhibitor, and with thapsigargin, a $\mathrm{Ca}^{2^{\prime}-}$ ATPase inhibitor of the endoplasmic reticulum, abolished the generation of pacemaker currents and suppressed the GTS-induced action. However, treatment with chelerythrine and calphostin $\mathbf{C}$, protein kinase $\mathbf{C}$ inhibitors, did not block the GTS-induced effects on the pacemaker currents. These results suggest that ginsenosides modulate the pacemaker activities of the ICC, and the ICC can be targets for ginsenosides, and their interaction can affect intestinal motility.
\end{abstract}

Key words ginseng total saponin; interstitial cells of Cajal; pacemaker current; gastrointestinal motility

Ginseng, the root of Panax ginseng C. A. MeYer, is a wellknown folk medicine and has been used as a tonic agent. The main molecular components responsible for the action of ginseng are the ginsenosides, which are also known as ginseng saponins. Ginsenoside is one of the derivatives of the triterpenoid dammarane consisting of 30 carbon atoms. ${ }^{1)}$ Ginsenoside has a four-ring, steroid-like structure with sugar moieties attached, and about 30 different forms have been isolated and identified from the root of Panax ginseng.

Several reports have demonstrated that ginsenosides exerts a variety of biological activities affecting the cardiovascular system, central or peripheral nervous system, and the immune system. ${ }^{2-4)}$ Interestingly, many studies have demonstrated that ginsenosides have an effect on the GI tract. Our interest was initially aroused by reports that showed an improvement in small intestinal transit with ginsenoside treatment. ${ }^{5-7)}$ However, it is still unclear how ginsenosides exert their pharmacologic or physiologic effects in the GI tract.

Interstitial cells of Cajal (ICC) are the pacemaking cells in the GI muscles that generate the rhythmic oscillations in the membrane potential known as slow waves. ${ }^{89}$ Slow waves propagate within ICC networks, are conducted into smooth muscle cells via gap junctions, and initiate phasic contractions via activation of $\mathrm{Ca}^{2+}$ entry through L-type $\mathrm{Ca}^{2+}$ channels. Ablation of ICC networks by genetic means or through the inactivation of Kit receptors with neutralizing antibodies results in the elimination of slow wave activity and alterations in GI motility. ${ }^{10,11)}$ The pacemaker mechanism has been shown to involve rhythmic oscillations in the intracellular calcium concentration and involves $\mathrm{Ca}^{2+}$ release from D-myo-inositol 1,4,5-trisphosphate $\left(\mathrm{IP}_{3}\right)$ receptor-operated stores. Uptake of $\mathrm{Ca}^{2+}$ activates voltage-independent, $\mathrm{Ca}^{2+}$ - inhibited, nonselective cation channels. ${ }^{12)}$

As exposure to ginsenosides has an effect on GI motility and as ICC are pacemaking cells in the GI muscles, in the present study we examined whether ginsenosides have a specific action on the electrical properties of cultured ICC of the small intestine of mice.

\section{MATERIALS AND METHODS}

All experiments were performed according to the Guiding Principles for the Care and Use of Animals approved by the Ethics Committee of Chosun University and the National Institutes of Health Guide for the Care and Use of Laboratory Animals. Every effort was made to minimize both the number of animals used and their suffering.

Preparation of Cells Balb/C mice (8-13 d old) of either sex were anesthetized with ether and killed by cervical dislocation. The small intestines from $1 \mathrm{~cm}$ below the pyloric ring to the cecum were removed and were opened along the mesenteric border. The luminal contents were washed away with Krebs-Ringer bicarbonate solution. The tissues were pinned to the base of a Sylgard dish and the mucosa was removed by sharp dissection. Small strips of intestinal muscle were equilibrated in $\mathrm{Ca}^{2+}$-free Hank's solution containing $\mathrm{KCl} 5.36 \mathrm{~mm}, \mathrm{NaCl} 125 \mathrm{~mm}, \mathrm{NaOH} 0.336 \mathrm{~mm}, \mathrm{Na}_{2} \mathrm{HCO}_{3}$ $0.44 \mathrm{~mm}$, glucose $10 \mathrm{~mm}$, sucrose $2.9 \mathrm{~mm}$, and HEPES $11 \mathrm{~mm}$, adjusted to $\mathrm{pH} 7.4$ with Tris for $30 \mathrm{~min}$. After incubation for $15 \mathrm{~min}$ at $37^{\circ} \mathrm{C}$ with an enzyme solution containing collagenase $1.3 \mathrm{mg} / \mathrm{ml}$ (Worthington Biochemical, Lakewood, NJ, U.S.A.), bovine serum albumin $2 \mathrm{mg} / \mathrm{ml}$ (Sigma, St. Louis, MO, U.S.A.), trypsin inhibitor $2 \mathrm{mg} / \mathrm{ml}$ (Sigma), and ATP $0.27 \mathrm{mg} / \mathrm{ml}$, the cells were dispersed. Cells were plated onto 
sterile glass coverslips coated with murine collagen 2.5 $\mu \mathrm{g} / \mathrm{ml}$ (Falcon/BD Biosciences, Franklin Lakes, NJ, U.S.A.) in $35 \mathrm{~mm}$ culture dishes. The cells were then cultured at $37^{\circ} \mathrm{C}$ in a $5 \% \mathrm{CO}_{2}$ incubator in smooth muscle growth medium (Clonetics Corp., San Diego, CA, U.S.A.) supplemented with $2 \%$ antibiotics/antimycotics (Gibco, Grand Island, NY, U.S.A.) and murine stem cell factor $5 \mathrm{ng} / \mathrm{ml}$ (SCF, Sigma). ICC were identified immunologically with a monoclonal antibody for Kit protein $\left(\mathrm{ACK}_{2}\right)$ and were labeled with Alexa Fluor 488 (Molecular Probes, Eugene, OR, U.S.A.).

Patch-Clamp Experiments The whole-cell configuration of the patch-clamp technique was used to record membrane currents (voltage clamp) and membrane potentials (current clamp) from cultured ICC. Currents or potentials were amplified using Axopatch 1-D (Axon Instruments, Foster City, CA, U.S.A.). A command pulse was applied using an IBM compatible personal computer and pClamp software (version 6.1; Axon Instruments). The data were filtered at $5 \mathrm{kHz}$ and displayed on an oscilloscope, computer monitor, and pen recorder (Gould 2200, Gould, Valley View, $\mathrm{OH}$, U.S.A.). The results were analyzed using pClamp and Graph Pad Prism (version 2.01) software. All experiments were performed at $30^{\circ} \mathrm{C}$.

Solutions and Drugs The cells were bathed in a solution containing $\mathrm{KCl} 5 \mathrm{~mm}, \mathrm{NaCl} 135 \mathrm{~mm}, \mathrm{CaCl}_{2} 2 \mathrm{~mm}$, glucose $10 \mathrm{~mm}, \mathrm{MgCl}_{2} 1.2 \mathrm{~mm}$, and HEPES $10 \mathrm{~mm}$ adjusted to $\mathrm{pH}$ 7.2 with Tris. The pipette solution contained K-aspartate $120 \mathrm{~mm}, \mathrm{KCl} 20 \mathrm{~mm}, \mathrm{MgCl}_{2} 5 \mathrm{~mm}, \mathrm{~K}_{2}$ ATP $2.7 \mathrm{~mm}, \mathrm{Na}_{2} \mathrm{GTP}$ $0.1 \mathrm{~mm}$, creatine phosphate disodium $2.5 \mathrm{~mm}$, EGTA $0.1 \mathrm{~mm}$, and HEPES $5 \mathrm{~mm}$, adjusted to $\mathrm{pH} 7.2$ with Tris. The drugs used were guanosine $5^{\prime}$-[ $\beta$-thio $]$ diphosphate trilithium salt (GDP- $\beta$-S), U-73122, calphostin C, chelerythrine, and thap- sigargin. All drugs were purchased from Sigma. Flufenamic acid and niflumic acid were purchased from Calbiochem ( $\mathrm{La}$ Jolla, CA, U.S.A.). The Korean Ginseng Cooperation (Taejon, Korea) kindly provided ginseng total saponins (GTS).

Statistical Analysis Data are expressed as the mean \pm standard errors. Differences in the data were evaluated using Student's $t$ test. A $p$ value less than 0.05 was taken as a statistically significant difference. The $n$ values reported in the text refer to the number of cells used in the patch-clamp experiments.

\section{RESULTS}

Effect of GTS on Slow Waves and Pacemaker Currents of Cultured ICC ICC cultured from the murine small intestine were identified by Kit immunofluroescence. Cells positive for Kit protein had a distinctive morphology that was easily recognized in the cultures. ${ }^{13)}$ Recordings from the cultured ICC under the current clamp mode $(I=0)$ showed spontaneous pacemaker potentials. The resting membrane potential was $-51 \pm 2 \mathrm{mV}$ and the amplitude was $22 \pm 4 \mathrm{mV}$. In the presence of GTS $(10 \mu \mathrm{g} / \mathrm{ml})$, the membrane potentials were depolarized to $-32 \pm 5.4 \mathrm{mV}$, and the amplitude of the pacemaker potentials was decreased to $2.4 \pm 1.1 \mathrm{mV}(n=5$, Fig. $1 \mathrm{~A}$, data not shown). Converting the amplifier to the voltageclamp mode at a holding potential of $-70 \mathrm{mV}$, ICC generated spontaneous inward currents called pacemaker currents and GTS produced tonic inward currents and decreased the frequency and amplitude of the pacemaker currents in a dosedependent manner (Figs. 1B-D). The summarized values and a bar graph showing the GTS effects on the pacemaker currents are indicated in Figs. $1 \mathrm{E}, \mathrm{F}$, and $\mathrm{G}(n=4)$.

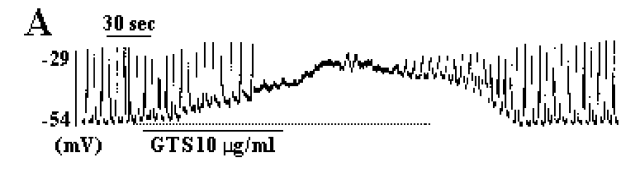

B

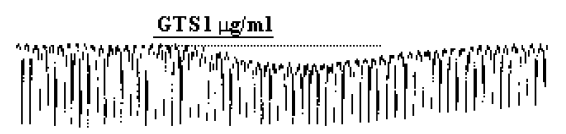

C

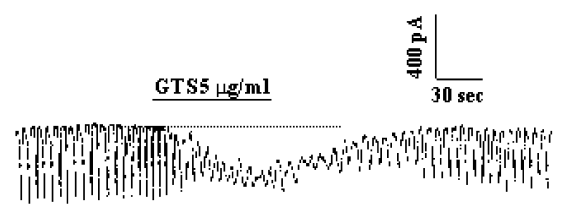

D

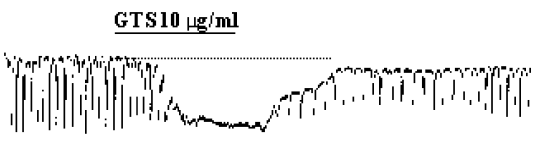

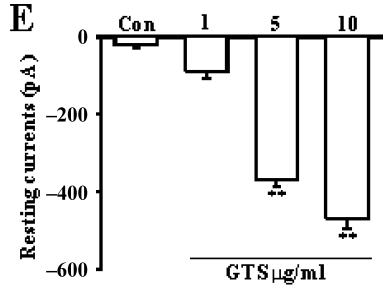
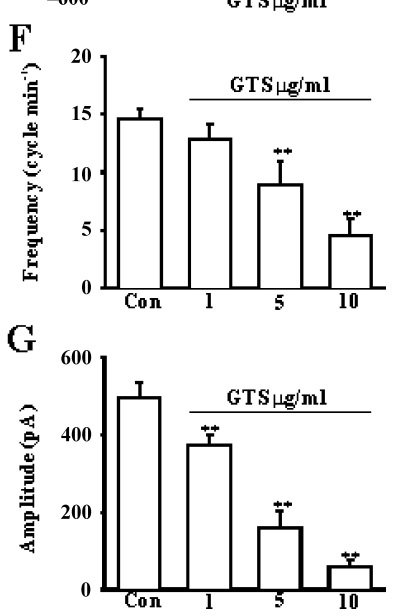

Fig. 1. Effects of GTS on Pacemaker Potentials and Pacemaker Currents Recorded in Cultured ICC from Murine Small Intestine

(A) Pacemaker potentials of ICC exposed to GTS $(10 \mu \mathrm{g} / \mathrm{ml})$ in the current-clamping mode $(I=0)$. Vertical solid line scales amplitude of pacemaker potential and horizontal solid line scales for duration of recording(s) pacemaker potentials. (B), (C), and (D) Pacemaker currents of ICC recorded at a holding potential of -70 mV exposed to various concentrations of GTS $(1,5,10 \mu \mathrm{g} / \mathrm{ml})$. The dotted lines indicate zero current levels. Vertical solid line scales amplitude of pacemaker current and horizontal solid line scales duration of recording (s) pacemaker currents. The responses to GTS are summarized in (E), (F) and (G). The bars represent mean values \pm S.E. $* *$ Significantly different from the untreated control (Con) $(p<0.01)$. 
A

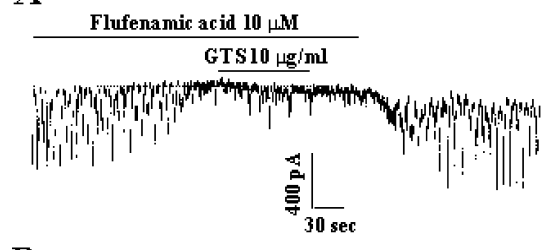

B

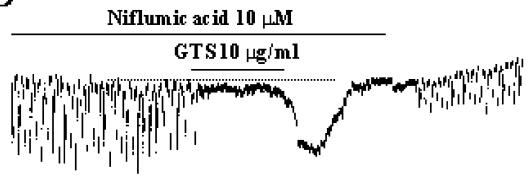

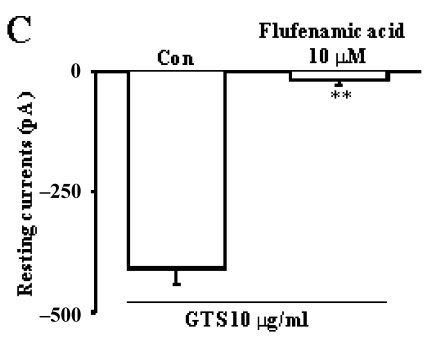

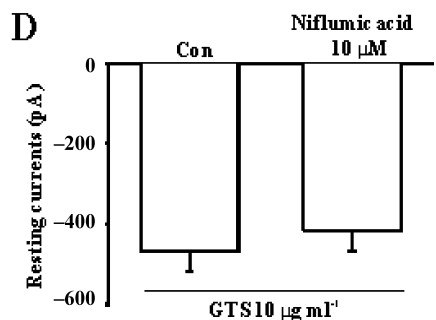

Fig. 2. Effects of Flufenamic Acid or Niflumic Acid on GTS-Induced Responses on Pacemaker Currents of Cultured ICC of Murine Small Intestine

(A) Application of flufenamic acid $(10 \mu \mathrm{M})$ abolished the generation of pacemaker currents. Under these conditions, the GTS (10 $\mu \mathrm{g} / \mathrm{ml})$ did not produce tonic inward currents. (B) Niflumic acid $(10 \mu \mathrm{M})$ also abolished the generation of pacemaker currents. However, niflumic acid did not block GTS (10 $\mu \mathrm{g} / \mathrm{ml})$-induced tonic inward currents. The dotted lines indicate zero current levels. Responses to the GTS in the presence of flufenamic acid or niflumic acid are summarized in (C) and (D). Vertical solid line scales amplitude of pacemaker current and horizontal solid line scales duration of recording(s) pacemaker currents. The bars represent mean values \pm S.E. $* *$ Significantly different from the untreated Control $(p<0.01)$.

A

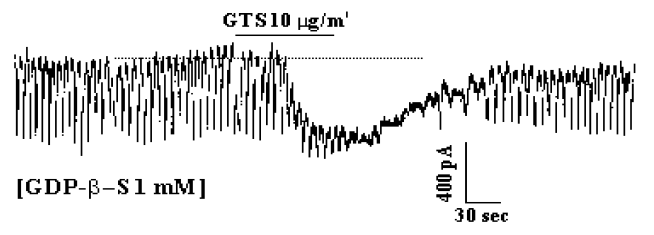

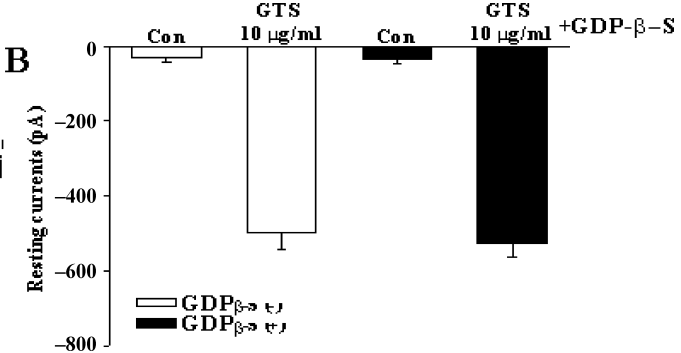

Fig. 3. Effects of GDP- $\beta$-S in Response to GTS Induced Pacemaker Currents from ICC of Murine Small Intestine

(A) Pacemaker currents from ICC exposed to GTS $(10 \mu \mathrm{g} / \mathrm{ml})$ in the presence of GDP- $\beta$-S $(1 \mathrm{~mm})$ in the pipette. The tonic inward currents with suppressed amplitudes and frequency induced by GTS remained unchanged in internally applied GDP- $\beta$-S (1 mM). The dotted lines indicate the zero current levels. The effects of GTS in the presence of GDP$\beta$-S are summarized in (B). Vertical solid line scales amplitude of pacemaker current and horizontal solid line scales for duration of recording(s) pacemaker currents. Bars represent mean values \pm S.E. The effects of GDP- $\beta$-S on GTS-induced pacemaker currents were not significantly different from the GTS-induced pacemaker currents $(p<0.01)$.

Effects of a Nonselective Cation Channel Blocker or a $\mathrm{Cl}^{-}$Channel Blocker on GTS-Induced Responses of Cultured ICC To determine the characteristics of the tonic inward currents produced by GTS, flufenamic acid, a nonselective cation channel blocker, or niflumic acid, a $\mathrm{Cl}^{-}$channel blocker, was examined. In the presence of flufenamic acid $(10 \mu \mathrm{M})$, the pacemaker current was abolished and the subsequent application of GTS $(10 \mu \mathrm{g} / \mathrm{ml})$ did not produce tonic inward currents (Fig. 2A). The resting current produced by GTS was $-24 \pm 7 \mathrm{pA}$ in the presence of flufenamic acid, and this value was significantly different when compared with the control conditions ( $n=4$, Fig. $2 \mathrm{C})$. In the presence of niflumic acid $(10 \mu \mathrm{M})$, the pacemaker currents were also abolished, although GTS still produced tonic inward currents (Fig. 2B). In the presence of niflumic acid, the resting current produced by GTS was $-126 \pm 12 \mathrm{pA}$; this value was not significantly different when compared with the control values obtained in the absence of niflumic acid ( $n=5$, Fig. 2D).

No Involvement of $G$ Proteins on GTS-Induced Tonic Inward Currents of Cultured ICC The effects of guanosine $5^{\prime}$-[ $\beta$-thio]diphosphate trilithium salt (GDP- $\beta$-S), a nonhydrolyzable guanosine $5^{\prime}$-diphosphate analogue that perma- nently inactivates GTP binding proteins were examined to determine whether G-protein has a role in the effects mediated by GTS in the ICC. When GDP- $\beta$-S ( $1 \mathrm{~mm})$ was in the pipette, GTS $(10 \mu \mathrm{g} / \mathrm{ml})$ still produced the tonic inward currents (Fig. 3A). In the presence of GDP- $\beta$-S in the pipette, the resting current was $-23 \pm 9 \mathrm{pA}$. With the application of GDP- $\beta$-S $1 \mathrm{~mm}$, the resting current produced by GTS was $-526.2 \pm 36 \mathrm{pA}(n=4$, Fig. 3B). This result indicates that Gproteins are not involved in the GTS-induced effects on pacemaker currents of the ICC.

Effects of an External $\mathrm{Ca}^{2+}$-Free Solution and $\mathrm{Ca}^{2+}$ ATPase Inhibitor of the Endoplasmic Reticulum in GTSInduced Responses of Cultured ICC To investigate the role of external $\mathrm{Ca}^{2+}$ or internal $\mathrm{Ca}^{2+}$, GTS was tested under external $\mathrm{Ca}^{2+}$-free conditions and in the presence of thapsigargin, a $\mathrm{Ca}^{2+}$-ATPase inhibitor of the endoplasmic reticulum. Pacemaker currents recorded at a holding potential of $-70 \mathrm{mV}$ were completely abolished by external $\mathrm{Ca}^{2+}$-free solution, and the GTS-induced tonic currents were blocked ( $n=5$, Fig. 4A). Under external $\mathrm{Ca}^{2+}$-free conditions, the value of the resting currents with GTS $(10 \mu \mathrm{g} / \mathrm{ml})$ was significantly different when compared with GTS $(10 \mu \mathrm{g} / \mathrm{ml})$ in the 
A
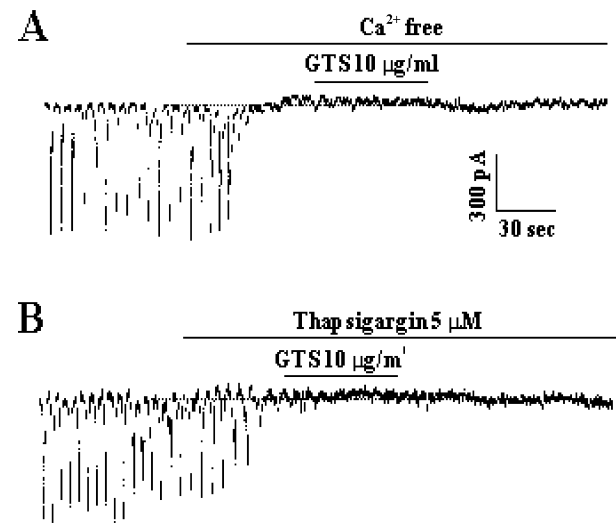

C
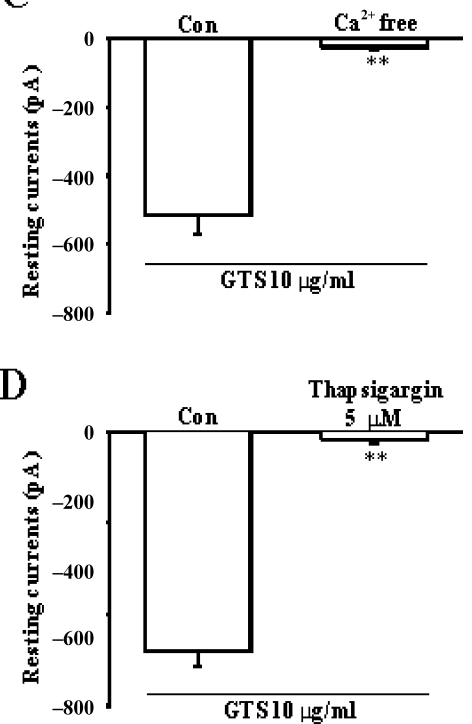

Fig. 4. Effects of an External $\mathrm{Ca}^{2+}$-Free Solution or Thapsigargin on the GTS-Induced Response on Pacemaker Currents of Cultured ICC of Murine Small Intestine

(A) External $\mathrm{Ca}^{2+}$-free solution abolished the generation of pacemaker currents. Under this condition, the GTS (10 $\left.\mu \mathrm{g} / \mathrm{ml}\right)$-induced tonic inward currents were blocked. (B) Thapsigargin $(5 \mu \mathrm{M})$ abolished the generation of pacemaker currents. Thapsigargin also blocked the GTS $(10 \mu \mathrm{g} / \mathrm{ml})$-induced tonic inward currents. The dotted lines indicate the zero current levels. Responses to the GTS in the external $\mathrm{Ca}^{2+}$-free solution and in the presence of thapsigargin are summarized in (C) and (D). Vertical solid line scales amplitude of pacemaker current and horizontal solid line scales duration of recording(s) pacemaker current. The bars represent mean values \pm S.E. $* *$ Significantly different from the untreated Control $(p<0.01)$.

A

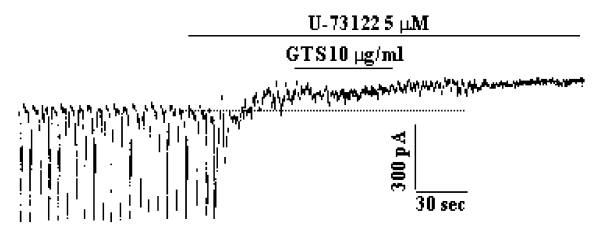

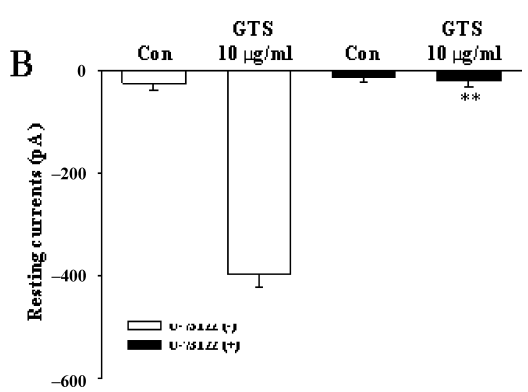

Fig. 5. Effects of U-73122 on the GTS-Induced Response on Pacemaker Currents of Cultured ICC of Murine Small Intestine

(A) U-73122 (5 $\mu \mathrm{M})$ abolished the generation of pacemaker currents. U-73122 also blocked the GTS (10 $\mu \mathrm{g} / \mathrm{ml})$-induced tonic inward currents. The dotted lines indicate the zero current levels. Responses to the GTS are summarized in (B). Vertical solid line scales amplitude of pacemaker current and horizontal solid line scales for duration of recording(s) pacemaker current. The bars represent mean values \pm S.E. ** The effects of U-73122 on GTS-induced pacemaker currents was significantly different from the GTS-induced pacemaker currents $(p<0.01)$.

normal $\mathrm{Ca}^{2+}$ solution (Fig. 4C). In addition, GTS-induced tonic inward currents were inhibited by pretreatment with thapsigargin (Fig. 4B). In the presence of thapsigargin $(5 \mu \mathrm{M})$, the value of the resting current with GTS treatment was significantly different when compared with GTS treatment in the absence of thapsigargin ( $n=4$, Fig. 4D).

Effects of a Phospholipase C Inhibitor on GTS-Induced Tonic Inward Currents of Cultured ICC Since the tonic inward currents produced by GTS treatment were related with intracellular $\mathrm{Ca}^{2+}$ mobilization, it is likely that the production of the GTS-induced effects on pacemaker currents require phospholipase $\mathrm{C}$ (PLC) activation. To test this possibility, GTS-induced tonic inward currents were measured in the presence and absence of U-73122, an active PLC inhibitor. Pacemaker currents recorded at a holding potential of $-70 \mathrm{mV}$ were completely abolished by application of $\mathrm{U}$ $73122(5 \mu \mathrm{M})$. In the presence of U-73122, the tonic inward current produced by GTS was $-21 \pm 11 \mathrm{pA}$. The value of the resting currents produced by GTS treatment was significantly different when compared with GTS treatment in the absence of U-73122 ( $n=5$, Fig. 5B). This result shows that the PLC inhibitor blocked the GTS-induced tonic inward currents of the ICC.

Effects of a Protein Kinase C Inhibitor in the GTS-Induced Responses of Cultured ICC We examined the effects of chelerythrine or calphostin $\mathrm{C}$, inhibitors of protein kinase $C$, to investigate whether the GTS-induced responses to pacemaker currents are mediated by the activation of protein kinase $\mathrm{C}$. Chelerythrine $(1 \mu \mathrm{M})$ or calphostin $\mathrm{C}(1 \mu \mathrm{M})$ did not have an effect on the tonic inward currents induced by GTS $(10 \mu \mathrm{g} / \mathrm{ml})$ (Figs. 6A, B). The value also was not significantly different when compared with the tonic inward currents induced by GTS obtained in the absence of chelerythrine or calphostin $\mathrm{C}(n=5$, Fig. $6 \mathrm{C})$. 
A

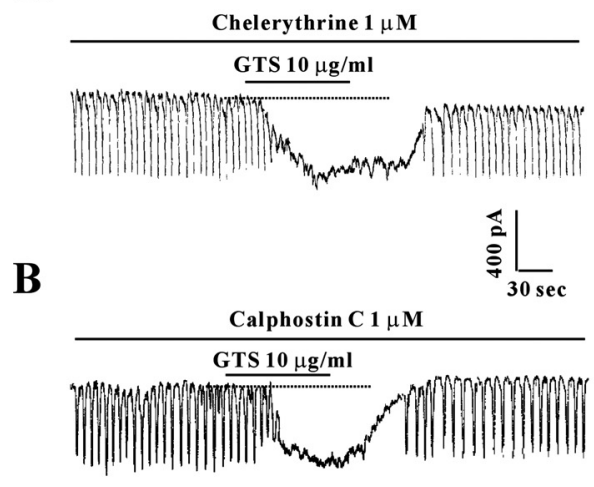

$\mathbf{C}$
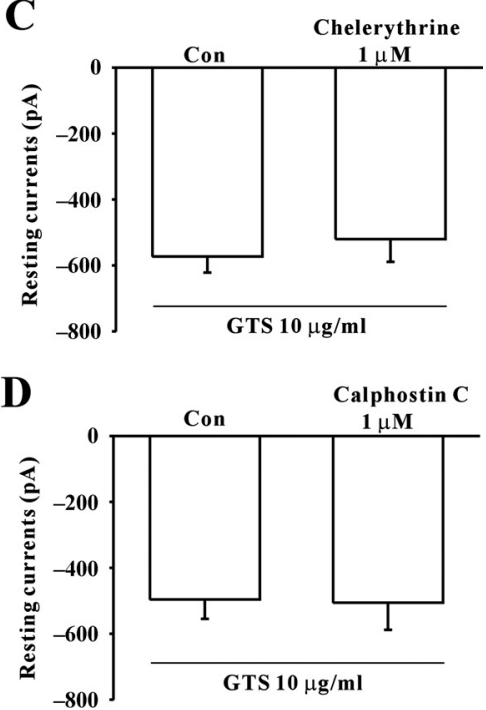

Fig. 6. Effects of Chelerythrine or Calphostin C on the GTS-Induced Response on Pacemaker Currents of Cultured ICC of Murine Small Intestine

(A), (B) Pacemaker currents of ICC exposed to GTS $(10 \mu \mathrm{g} / \mathrm{ml})$ in the presence of chelerythrine $(1 \mu \mathrm{M})$ or calphostin C $(1 \mu \mathrm{M})$. In this condition, the GTS caused tonic inward currents. The dotted lines indicate the zero current levels. Responses to the GTS in the presence of chelerythrine or calphostin C are summarized in (C). Vertical solid line scales amplitude of pacemaker current and horizontal solid line scales duration of recording(s) pacemaker current. The bars represent mean values \pm S.E.

\section{DISCUSSION}

Ginsenosides, active ingredients of Panax ginseng, have been widely used as invigorating agents for a long time and many reports showed a variety of physiologic or pharmacologic effects in various regions. ${ }^{14)}$ However, there are only a few reports on the effects of ginsenosides on GI motility. In the present study, we found that ginsenosides regulate intestinal motility by modulating the pacemaker currents of ICC and that this modulation is mediated via nonselective cation channels and intracellular $\mathrm{Ca}^{2+}$ mobilization in a protein kinase $\mathrm{C}$-independent manner.

ICC generate spontaneous pacemaker inward currents that depolarize the membrane; these spread to smooth muscle via gap junctions resulting in the depolarization of the membrane in smooth muscle and lead to contractions by generating an acting potential through voltage dependent $\mathrm{Ca}^{2+}$ channel activation. It has been suggested that pacemaker currents of the ICC are mediated by the activation of voltage-independent nonselective cation channels. ${ }^{15,16)}$ In the present study, we found that ICC produced spontaneous pacemaker inward currents under the voltage-clamp mode and the application of GTS evoked the tonic inward currents of the pacemaker currents. Our results also showed that flufenamic acid abolished the pacemaker current generation and that the GTS-induced tonic inward currents were blocked by flufenamic acid. These findings provide strongly support for the suggestion that nonselective cation channels may be involved in generating the pacemaker currents of the ICC and ginsenosides have a function in the regulation of pacemaker currents by regulating the nonselective cation channels of the ICC. Moreover, it has been reported that ICC exhibit inwardly rectifying $\mathrm{Cl}^{-}$currents that can be rhythmically activated and the $\mathrm{Cl}^{-}$currents may generate the rhythmic inward currents and be a stabilizing influence on ICC excitability. ${ }^{17)}$ In our results, although niflumic acid, a $\mathrm{Cl}^{-}$channel blocker, also abolished pacemaker generation, niflumic acid did not block the GTS-in- duced tonic inward currents. It is likely that both $\mathrm{Cl}^{-}$channels and nonselective cation channels contribute to the generation of the spontaneous pacemaker currents in the ICC and that ginsenosides may regulate nonselective cation channels.

Several reports have shown that ginsenosides share a common G-protein-coupled signaling pathway with well-defined neurotransmitters and are endogenous agents for their pharmacologic or physiologic actions. ${ }^{18-20)}$ For example, it has been shown that ginsenosides inhibit voltage-dependent $\mathrm{Ca}^{2+}$ channels in sensory neurons to the same degree as opiates through pertussis toxin-sensitive G-proteins and regulate the $\mathrm{Ca}^{2+}$ channel through an interaction with $\mathrm{G}$ proteins in rat chromaffin cells. It was also reported that G-proteins have an essential role in noradrenaline-induced effects on pacemaker currents in ICC. ${ }^{21)}$ However, in our study, when GDP- $\beta$-S was present in the pipette, the tonic inward currents of the pacemaker currents induced by GTS still were present. This indicates that the effects of ginsenosides on the electrical activity in ICC may not be related to G-proteins. An external $\mathrm{Ca}^{2+}$ influx is necessary for GI smooth muscle contractions and external $\mathrm{Ca}^{2+}$ was essential to generate pacemaker currents in ICC. In $\mathrm{Ca}^{2+}$-depleted medium, the pacemaking currents were abolished. ${ }^{22)}$ In the present study, the GTS-induced tonic inward current was suppressed in the external $\mathrm{Ca}^{2+}$-free solution. This shows that an external $\mathrm{Ca}^{2+}$ influx is necessary for the ginsenoside-induced tonic inward pacemaker currents.

Interestingly, some reports demonstrated that ginsenosides interact with unidentified membrane components at the extracellular side and induce a mobilization of $\mathrm{Ca}^{2+}$ from 1,4,5-inositol triphosphate $\left(\mathrm{IP}_{3}\right)$-sensitive intracellular stores via a PLC pathway in Xenopus oocytes. ${ }^{20,23)}$ It has also been suggested that external $\mathrm{Ca}^{2+}$ dependency, $\mathrm{IP}_{3}$ receptor activation, and PLC activation are involved in the main molecular mechanisms of ginsenoside-induced activation of the store operated $\mathrm{Ca}^{2+}$ entry process in Xenopus oocytes. ${ }^{24)}$ These observations suggest that ginsenosides may exert biological ac- 
tivity through the mobilization of intracellular $\mathrm{Ca}^{2+}$ and PLC activation. In addition, the generation of pacemaker currents was dependent upon intracellular $\mathrm{Ca}^{2+}$ oscillation. The periodic release of $\mathrm{Ca}^{2+}$ from the endoplasmic reticulum is essential for generating pacemaker currents. ${ }^{25)}$ In the present study, thapsigargin, a potent endoplasmic reticulum $\mathrm{Ca}^{2+}$ ATPase inhibitor, and U-73122, an active PLC inhibitor, suppressed the GTS-induced tonic inward currents. These results suggest that the release of $\mathrm{Ca}^{2+}$ from internal store and PLC activation by ginsenosides is essential to produce the tonic inward currents.

It has been shown that ginsenosides induce differentiation of human promyelocytic leukemia HL-60 cells into morphologic and functional granulocytes by modulating protein kinase $\mathrm{C}^{26)}$ and also the activation of protein kinase $\mathrm{C}$ is responsible for effects of ginsenosides on the gap junctionmediated intercellular communication function. ${ }^{27)}$ However, in the present study, chelerythrine or calphostin $\mathrm{C}$, specific potent protein kinase $\mathrm{C}$ inhibitors, did not block the GTSinduced effects, suggesting that protein kinase $\mathrm{C}$ is not involved in the response of ginsenosides in the ICC.

In conclusion, this study describes the effects of ginsenosides on the ICC in the murine small intestine. Ginsenosides depolarized the membrane with increased tonic inward currents, which was activated by nonselective cation channels via external $\mathrm{Ca}^{2+}$ influx, PLC activation, and $\mathrm{Ca}^{2+}$ release from internal storage in a protein kinase $\mathrm{C}$-independent manner. Thus the GTS may play an important role in the regulation of GI motility by acting on the ICC.

Acknowledgments This work was supported by Korea Research Foundation Grant funded by Korea Government (MOEHRD, Basic Research Promotion Fund) (KRF-2005003E00011) and Regional Research Centers Program (Biohousing) of the Korean Ministry of Education \& Human Resources Development (2007).

\section{REFERENCES}

1) Nah S. Y., Korea J. Ginseng Sci., 21, 1-12 (1997).

2) Saito H., Tsuchiya M., Naka S., Takagi K., Jpn. J. Pharmacol., 27, 509-516 (1977)

3) Chen X., Clin. Exp. Pharmacol. Physiol., 23, 728-732 (1996).
4) Gillis C. N., Biochem. Pharmacol., 54, 1-8 (1997).

5) Furukawa Y., Shiga Y., Hanyu N., Hashimoto Y., Mukai H., Nishikawa K., Aoki T., Jpn. J. Gastroenterol. Surg., 28, 956-960 (1995).

6) Hashimoto K., Satoh K., Kase Y., Ishige A., Kubo M., Sasaki H., Nishikawa S., Kurosawa S., Yakabi K., Nakamura T., Planta Med., 67, 179-181 (2001).

7) Murata P., Hayakawa T., Satoh K., Kase Y., Ishige A., Sasaki H., Phytother. Res., 23, 29-41 (2001).

8) Sanders K. M., Gastroentrology, 111, 492-515 (1996).

9) Huizinga J. D., Robinson T. L., Thomsen L., Neurogastroenterol. Motil., 12, 3-9 (2000).

10) Ward S. M., Burns A. J., Torihashi S., Sanders K. M., J. Physiol., 480, 91-97 (1994).

11) Torihashi S., Nishi K., Tokutomi Y., Nishi T., Ward S., Sanders K. M., Gastroenterology, 117, 140-148 (1999).

12) Koh S. D., Jun J. Y., Kim T. W., Sanders K. M., J. Physiol., 540, 803814 (2002).

13) Jun J. Y., Choi S., Chang I. Y., Yoon C. K., Jeong H. G., Kong I. D., So I., Kim K. W., You H. J., Br. J. Pharmacol., 144, 242-251 (2005).

14) Attele A. S., Wu J. A., Yuan C. S., Biochem. Pharmacol., 58, 16851693 (1999).

15) Koh S. D., Sanders K. M., Ward S. M., J. Physiol., 513, 203-213 (1998).

16) Thomsen L., Robinson T. L., Lee J. C. F., Farraway L., Hughes M. J. H., Andrews D. W., Huizinga J. D., Nature (London), 4, 848-851 (1998).

17) Huizinga Z. D., Zhu Y., Ye J., Molleman A., Gastroenterology, 123, 1627-1636 (2002).

18) Yoshimura H., Watanabe K., Ogawa N., Eur. J. Pharmacol., 146, 291-297 (1998).

19) Nah S. Y., McCleskey E. W., Proc. Natl. Acad. Sci. U.S.A., 92, 87398743 (1995).

20) Choi S., Kim H. J., Ko Y. S., Jeong S. W., Kim Y. I., Simonds W. F., Oh J. W., Nah S. Y., J. Biol. Chem., 276, 48797-48802 (2001).

21) Jun J. Y., Choi S., Yeum C. H., Chang I. Y., Park C. K., Kim M. Y., Kong I. D., So I., Kim K. W., You H. J., Br. J. Pharmacol., 141, 670677 (2004).

22) Tokutomi N., Maeda H., Tokutomi Y., Sato D., Sugita M., Nishigawa S., Nakao J., Imamura T., Nishi K., Pflügers Arch., 431, 169-177 (1995).

23) Choi S., Rho S. H., Jung S. Y., Kim S. C., Park C. S., Nah S. Y., Br. J. Pharmacol., 132, 641-648 (2001).

24) Jeong S. M., Lee J. H., Kim S., Rhim H., Lee B. H., Kim J. H., Oh J. W., Lee S. M., Nah S. Y., Br. J. Pharmacol., 142, 585-593 (2004).

25) Ward S. M., Ordog T., Koh S. D., Baker A., Jun J. Y., Amberg G., Monaghan K., Sanders K. M., J. Physiol., 525, 355-361 (2000).

26) Kim Y. S., Kim D. S., Kim S. I., Int. J. Biochem. Cell Biol., 30, $327-$ 338 (1998).

27) Zhang Y. W., Dou D. Q., Zhang L., Chen Y. J., Yao X. S., Planta Med., 67, 417-422 (2001). 